\title{
REFLEXÕES SOBRE O USO DA LINGUAGEM E DA IMAGEM NA PESQUISA HISTÓRICA DO ESPORTE: A TRAJETÓRIA DE BLANCHE PIRONNET NA HISTÓRIA DAS MULHERES NO ESPORTE NO BRASIL
}

REFLECTIONS ABOUT THE USE OF LANGUAGE AND IMAGE IN HISTORIC RESEARCH ON SPORT: THE TRAJECTORY OF BLANCHE PIRONNET IN THE HISTORY OF WOMEN IN SPORTS IN BRAZIL

REFLEXIONES SOBRE EL USO DEL LENGUAJE Y LA IMAGEN EN LA INVESTIGACIÓN HISTÓRICA EN EL DEPORTE: LA TRAYECTORIA DE BLANCHE PIRONNET EN LA HISTORIA DE LAS MUJERES EN EL DEPORTE EN BRASIL

Fabiano Pries Devide*

Palavras chave

História.

Mulheres.

Esporte.

Gênero.

Keywords

History.

Women.

Sport.

Gender.

Palabras clave:

Historia.

Mujeres.

Deporte.

Género.
Resumo: 0 presente estudo tem por objetivo propor uma reflexão sobre o uso da linguagem, através do discurso e da imagem como fontes para a investigação histórica do esporte. Para tal, a partir da História Oral e da Semiótica, apresenta a trajetória da nadadora Blanche Pironnet na cidade de São Paulo, no início do século XX (1910-1920), como uma referência no estudo da História das Mulheres no esporte no Brasil. 


\section{INTRODUÇÃO}

Esta pesquisa tem o objetivo de refletir sobre o uso da linguagem e da imagem como fontes para a pesquisa em História do Esporte, a partir da trajetória da nadadora Blanche Pironnet, uma referência no estudo da História das Mulheres no esporte, especificamente na natação, no Brasil. Para a análise dos dados reunidos neste estudo, procedemos à ordenação das fontes (representadas pelos jornais, revistas, imagens e entrevista de elite com a colaboradora), e à interpretação pautada em referenciais teóricos e metodológicos como a História das Mulheres ${ }^{1}$, a História $\mathrm{Oral}^{2}$ e a Semiótica. Atemo-nos à investigação das práticas sociais através da linguagem ${ }^{3}$ e da imagem, através das quais construímos as interpretações sobre a participação de Blanche Pironnet como uma referência na História das Mulheres no esporte no Brasil.

Organizamos os pontos de vista e as fontes históricas ${ }^{4}$, atribuindo-Ihes uma interpretação, reconhecendo que a história de leitura e a memória discursiva do historiador influenciam sua abordagem às fontes escritas, orais ou iconográficas, reconstituindo e apreendendo o objeto de estudo com sua subjetividade.

Os historiadores, hoje, têm inovado ao adotar novas fontes históricas, além das oficiais, caracterizando uma revolução documental, com o uso de "novos textos", que não os escritos (MAUAD, 1996; CARDOSO, MAUAD, 1997). Alguns se voltam para o depoimento oral, outros para as imagens (GASKELL, 1992). Descobrem fontes constituídas sem a intenção futura de reconstruírem a história de um grupo, indivíduo, comunidade ou nação. A interpretação de fontes desta natureza tem exposto o pesquisador a críticas severas ${ }^{5}$, uma vez que "os critérios para a interpretação dos significados latentes, em particular, são na verdade difíceis de ser formulados" (BURKE, 1992, p. 27).

\section{TRAJETÓRIA ESPORTIVA DE BLANCHE PIRONNET}

Descobrimos a existência de Blanche Pironnet numa visita ao Arquivo Histórico do Clube Esperia (CE), em São Paulo. Entrevistei-a ${ }^{6}$ em sua residência, quando deu seu testemunho sobre suas participações nas Festas Esportivas da Societá Italiana di Canottieri, em 1919, que se tornaria o $\mathrm{CE}$, localizado às margens do rio Tietê.

\footnotetext{
$1 \mathrm{~A}$ História das Mulheres tem buscado incluí-las como sujeitos da sua própria história, oferecendo uma nova leitura de verdades históricas estabelecidas (SCOTT, 1992; SOIHET, 1997). A História deve ser suplementada com informações sobre as experiências vividas por mulheres, revendo a História oficial. A História das Mulheres se consolidou e legitimou quando afirmou a experiência singular das mulheres, criando uma identidade coletiva e afirmando a sua diferença (SCOTT, 1992).

2 A História Oral é uma metodologia para a elaboração de documentos, arquivamento e pesquisas referentes à vida de pessoas, acontecimentos, tradições, rituais. Estabelece e ordena procedimentos, tendo como base a evidência oral. Recupera a experiência daqueles que ficaram à sombra da narrativa histórica oficial, tomando como foco o colaborador. É um espaço interdisciplinar, que fornece interpretações centradas nas representações e narrativas dos colaboradores (LOZANO, 1996). Tem fornecido um caráter revisionista à história tradicional, pelo uso da evidência oral no esclarecimento de trajetórias individuais ou dos fatos subjetivos encobertos pela filtragem racionalista dos documentos oficiais (THOMPSON, 1992; FERREIRA \& AMADO, 1996; MEIHY, 1996; ETIÉNNE, 1996). Isto proporciona aos historiadores uma descrição densa dos relatos construídos por ocasião da entrevista. Segundo Thompson (1992, p. 137): "Enquanto os historiadores estudam os atores da história à distância, a caracterização que fazem de suas vidas, opiniões e ações sempre estarão sujeitas a serem descrições defeituosas, projeções da experiência e da imaginação do próprio historiador [...]. A evidência oral, transformando os 'objetos' de estudo em 'sujeitos', contribui para uma história [...] mais 'verdadeira".

3 Neste estudo, nos aproximamos da abordagem pragmática, na qual a linguagem é encarada como ferramenta: ao dizer, o sujeito age no mundo, pois sua fala provoca crenças e desencadeia atitudes nos interlocutores (COSTA, 1994; RORTY, 1994).

40 caminho para construção do conhecimento histórico pressupõe reflexão teórica constante, um trabalho empírico e vasto no campo de pesquisa, e um vínculo entre pesquisador-pesquisado(s).

5 Estas críticas recaem na interpretação, no que diz respeito ao conflito entre a intenção do autor da fonte, a intenção do leitor-intérprete (historiador), na interface do leitor da academia, representado pelos demais pesquisadores ou pessoas que têm acesso à pesquisa. Sejam quais forem as críticas, não há dúvida de que a interpretação seja efetuada em uma quantidade e variedade rica de fontes sobre os temas pesquisados, possibilitando uma "descrição densa", em virtude de sua contextualização (SHARPE, 1992). 
Belga, nascida em 1903, em Verviers, seu pai lhe ensinou as primeiras braçadas em um riacho. Chefe de tecelões, ele veio trabalhar no Rio de Janeiro, em 1911, trazendo a família no ano seguinte. Aos domingos, acompanhada do pai e de amigos, Blanche ia à praia Vermelha nadar. Pela manhã, descreve em detalhes as sessões de ginástica calistênica e exercícios respiratórios que fazia sob a supervisão de seu pai, junto com o irmão, José Pironnet: "[...] antes de irmos para a escola, nós fazíamos ginástica com o meu pai. [...]. Era assim, uns halteres, sabe? Pequenininhos. [...] era questão de 15, 20 minutos. [...] Meu pai tinha livros, em casa, de ginástica [...]" (PIRONNET, 2001).

Em 1917, o pai foi trabalhar em São Paulo, onde a família fixaria residência. Associaramse ao CE. Ainda menina, Blanche despertou curiosidade ao nadar no canal formado por um desvio do rio Tietê no terreno do clube. O pai a esperava na margem, para cobri-la com um roupão, o que retrata a resistência da sociedade às mulheres que se expunham em público em trajes de banho.

Tinha o que se chamava o canal, era uma entrada de água [...], nós íamos nadar lá. [...] foi assim: "Uma mulher está nadando! [...]", foi uma coisa [risos] e meu pai imediatamente [...] veio com um roupão para me cobrir quando eu saía da água... Em resumo: bobagem de época... Eu era muito moça, e eu não sei se incomodava. (PIRONNET, 2001)

Em São Paulo, Blanche saía da Escola Álvares Penteado, no Largo de São Francisco, pegava o bonde até a Ponte Grande, indo ao $\mathrm{CE}$, onde encontrava o irmão. Lá, pegavam uma carona de barco até a Ponte, saltavam na água e desciam o rio nadando até o canal que se formava no clube.

Em 1919, nas Festas do CE, Blanche foi única mulher entre os participantes das provas de natação, sagrando-se vencedora, utilizando o over arm side stroke ${ }^{7}$, enquanto os homens nadavam o nado clássico. Em 23 de fevereiro de 1919, o CE realizou sua "Festa Sportiva Social na Ponte Grande", célula mater do esporte aquático paulistano (NICOLINI, 2001). Numa das duas provas de natação do programa, o "9ำ páreo - 350 metros rio abaixo", encontrava-se inscrita, entre seis concorrentes, Blanche Pironnet:

A Senhorita Blanche Pironnet venceu brilhantemente e em bello estylo o pareo de natação [...], recebendo na chegada fartos aplausos. A presença dessa jovem nas nossas corridas de natação é um estimulo para a participação do bello sexo nas festas nauticas das nossas sociedades. (DIARIO,1919, p. 2) $)^{8}$.

Se até então o esporte tinha como objetivo principal o culto à graça e à beleza femininas (SCHPUN, 1999), a possibilidade de uma mulher disputar e vencer os homens em uma competição contribuiu para mostrar que as mulheres podiam competir, serem atléticas e fortes, desconstruindo o fundamento do discurso normativo da época, que buscava nas diferenças naturais entre os sexos elementos que determinavam quais práticas físicas eram ideais para as mulheres e para os homens.

Blanche Pironnet ganhou visibilidade na sociedade paulistana repetindo suas vitórias em outras ocasiões, no mesmo ano de 1919. Em julho, nas "Festas Sportivas em commemoração do XX anniversario da fundação do Club Esperia", venceu o "9oáreo - natação - qualquer

\footnotetext{
7 Neste estilo, o executante se colocava numa posição lateral, diminuindo o atrito com a água, melhorando a propulsão, sendo mais veloz do que o estilo clássico. Blanche relembra: "eu tomei parte nas corridas e eu era a única mulher [...]. E... eu ganhei [...] o esporte era pouco desenvolvido. E os rapazes nadavam braçada clássica [...] e eu nadava de lado [...]. Era o [nado] que nadava mais depressa" (PIRONNET, 2001).

8 Diario Popular, São Paulo, 24 fev.1919, ano XXXV, n. 11842, p. 2.
} 
classe, 350 metros rio abaixo", vencendo dois concorrentes do "sexo forte". A imprensa fazia previsões:

No pareo de natação [...] tomará parte [...] a eximia "nageuse" senhorita Blanche Pironnet, que na ultima festa do Esperia levantou brilhantemente o primeiro premio [...]. Alexandre Conte e Spartaco Remeti são os companheiros de corrida da applaudida nadadora [...]. A senhorita Pironnet saberá, mais uma vez, derrotar os seus collegas, mantendo intactas as suas tradicções sportivas (DIARIO, 1919, p. 2) $)^{9}$.

Os jornais não debatem as diferenças físicas "naturais" entre os homens e as mulheres, que serviam de meio para que elas, "frágeis", fossem excluídas de algumas práticas esportivas. Blanche desconstruía argumentos biologicistas, calando aqueles que por inúmeras vezes assumiam o discurso que repreendia a participação feminina em competições esportivas.

O CE, reconhecendo o pioneirismo de Blanche, convidou-a a ser diretora da seção feminina de natação. Em novembro de 1919, ela venceu seis homens na prova de "500 metros rio abaixo", tendo a sua vitória sobre os concorrentes do "sexo forte" enaltecida:

Mais uma vez a senhorita Blanche Pironnet, [...] demonstrou as suas excellentes qualidades de "nageuse", conseguindo brilhantemente vencer esse pareo, deixando os demais concorrentes do sexo forte a distancia consideravel. A chegada da vencedora foi saudada com vibrantes orações de jubilo e applausos geraes. (DIARIO, 1919, p. 2). ${ }^{8}$

Em 1921, Blanche participou como única paulista da primeira prova interestadual de natação feminina, no Rio de Janeiro ${ }^{10}$. A prova de 200 metros, "Nylsa e Nadir de Medeiros", na enseada de Botafogo, teve audiência numerosa com a presença da imprensa. Dez competidoras demonstraram o aumento da participação das mulheres na natação feminina no Rio de Janeiro"1. O Imparcial trouxe uma entrevista com Blanche Pironnet: "Até hoje invencivel na Paulicéa"; e o Correio da Manhã destacou a prova feminina do concurso aquático:

Sallienta-se desse magnífico programma a interessante prova feminina que tem sido o 'clou' das festas aquaticas realizadas entre nós e que terá de ser disputada por 10 eximias nadadoras, para a disputa do titulo conquistado das vezes anteriores pelas valentes nadadoras do C.R.S. Christovão [...]. Esta prova terá ainda como seria concorrente a nadadora paulista do Club Esperia [...] (Correio da Manhã ${ }^{12}$, Rio de Janeiro, 3 abr. 1921, grifos nossos).

A presença de uma prova feminina era garantia de sucesso de audiência nas competições. Se até aquela data as mulheres nadavam e competiam entre os muros de seus clubes, o concurso aquático de abril de 1921 foi um marco na história da natação feminina carioca, chamando a atenção da imprensa. O esporte era via de conquista de espaço na esfera pública das competições de natação, predominantemente masculinas em sua audiência e em seus concorrentes (DEVIDE, 2003, 2012).

Após a prova, Ophelia Paranhos, carioca favorita à vitória, desmaiou ao completar 0 percurso. O Correio da Manhã criticou a Federação Brasileira das Sociedades do Remo pela metragem e intensidade da prova para nadadoras jovens, trazendo à tona argumentos sobre

9 Diario Popular, São Paulo, 9 jul.1919, ano XXXV, n. 11954, p. 2.

10 "Eu [...] achei assim mais importante, quando eu fui representar o Esperia no Rio de Janeiro. [...] Eu era a única paulista" (PIRONNET, 2001). 11 É importante lembrar que dois anos antes, em São Paulo, Blanche nadava contra os homens, em provas no rio Tietê, uma vez que não havia mulheres inscritas para competir com ela (FBSR, 1921). 
a contraindicação da competição esportiva para as mulheres, tal como Fernando de Azevedo (1920, p. 46) e outros intelectuais já preconizavam: "Os exercícios para a mulher (porque a sua estructura é mais fraca e delicada do que a do homem) devem ser menos enérgicos e ter menos duração. É contra indicado todo e qualquer exercício que exija dispêndio muscular intenso e prolongado".

A vitória sobre a favorita Ophelia ${ }^{13}$ tornou Blanche famosa no Rio de Janeiro, onde esta permaneceu com a família alguns dias, recebendo como prêmio, no Club de Natação e Regatas, um relógio de ouro com pulseira de fita, de Nilsa e Nadir Medeiros, que deram nome à prova ${ }^{14}$. Blanche também foi entrevistada e retratada - em nenhuma ocasião nadando - pela imprensa carioca:

[...] achei a assitencia bem distincta e cordial. Pouco posso dizer sobre as minhas rivaes [...]. Fiquei, entretanto, admirada de encontrar tantas senhoritas nadando 200 metros com facilidade; quando eu habitava o Rio, não haviam moças que se dedicasse a este sport [...]" (O Imparcial, Rio de Janeiro, abr. 1921) ${ }^{15}$.

Blanche reconhece o seu vanguardismo, incentivando a prática da natação entre as sócias do CE. Com a obrigatoriedade de saber nadar para poder remar, as mulheres, filhas de estrangeiros, tiveram que ingressar na natação e aprender com o pai de Blanche, que ministrava as aulas no CE. Assistiu às paulistas romperem os preconceitos sociais no esporte, e muitas colegas não aprenderem a nadar por imposição dos pais, que as proibiam de se expor em público em trajes de banho.

Às vezes as próprias moças se animavam, mas os pais é que impedem. [...] Porque decidiram: "Não fica bem". Sei lá se fica bem, se ficava ruim. Eu, lá em casa nunca teve esse negócio de dizer: "Não, não, pra uma moça não fica bem fazer isso". Por que não fica bem? (PIRONNET, 2001 - grifos nossos)

Blanche ressalta os avanços e espaços conquistados pelas mulheres, que hoje têm mais possibilidade de se manifestar. Considera que estava à frente de seu tempo, devido à influência paterna e à educação liberal que recebeu em casa: "[...] ele era avançado pra época. [...] Eu seguia as ideias de meu pai, e meu pai nunca achou que... nós [as mulheres] éramos mais fracas" (PIRONNET, 2001).

Em São Paulo, foi a primeira mulher contratada pelo Banco Francês Italiano, devido ao francês fluente e o domínio da taquigrafia. Trabalhou no Instituto do Café, naturalizando-se brasileira, e como secretária do assessor de Jânio Quadros ${ }^{16}$. 0 compromisso com a família e o trabalho a afastaram do esporte, por falta de tempo para treinar: "[...] eu parei de competir porque eu não podia treinar, trabalhando como eu trabalhava. [...] o banco [...] eu trabalhava das oito até as cinco e meia. [...] Então, não adiantava treinar só sábado e domingo" (PIRONNET, 2001). Em 1931, afastada das competições, em entrevista à Folha da Noite, Blanche ressaltou os avanços da prática do esporte pelas paulistas:

\footnotetext{
13 A revanche das cariocas sobre as paulistas se deu em fevereiro de 1924, quando a Federação Paulista das Sociedades de Remo (FPSR) organizou, em Santos, um concurso aquático e Ophelia Paranhos, única carioca, compareceu e venceu todas as concorrentes paulistas (O Imparcial, Rio de Janeiro, 24 fev. 1924, ano XIII, n. 4085, p. 14).

140 Imparcial, 6 abr. 1921 [AASP - Álbum de recortes. 1920. São Paulo: AASP].

15 Clube ESPERIA. Pasta "Blanche Pironnet", nำ21-A [recortes doados pela nadadora]. São Paulo: Esperia.

16 Foi com o desenvolvimento industrial e urbano que o acesso à escolaridade, o direito ao voto, a participação pública e 0 avanço do feminismo no Brasil permitiram às mulheres a conquista de espaços na área profissional, em determinadas funções reservadas ao sexo feminino, dependendo da autorização dos maridos, quando casadas, e desde que não pusessem o trabalho à frente dos deveres domésticos. Algumas das profissões assumidas por elas foram as de professora, taquígrafa, secretária, telefonista e operária de indústrias (MALUF, MOTT, 1998).
} 
São Paulo progrediu immenso na aquatica [...]. Principalmente entre as moças que conseguiram sobrepor a finalidade da cultura physica aos preconceitos sociaes, que se vivia eivada a sociedade no meu tempo (Folha da Noite, São Paulo, 12 mar. 1931, ano XI, n. 3113).

Como colaboradora, Blanche Pironnet é um exemplo de como as mulheres se destacavam na sociedade através da participação no esporte. O poder simbólico (BOURDIEU, 1999) que adquiriam ao se consagrarem vitoriosas possibilitava um rompimento aceitável com a esfera doméstica, e a conquista de espaços na vida pública (DEVIDE, 2003, 2012).

\section{REFLEXÕES SOBRE O ATO INTERPRETATIVO E O USO DA FOTOGRAFIA NA PESQUISA HISTÓRICA}

Eco (1997) considera que interpretar pressupõe "modificar" o texto do outro, atribuindo os nossos sentidos; o que remete a considerar que os signos possibilitam uma interpretação plural, não possuindo um sentido literal, a priori (PÊCHEUX, 1995). Os termos correntes na prática interpretativa são redescrever, reinterpretar, reconstruir, em substituição a reproduzir, descrever e analisar. 0 texto que busca dizer "isto é isto" corre o risco de não ser compreendido no universo interpretativo, em função do deslocamento do significado ${ }^{17}$.

Interpretar a ação humana pressupõe atentar para a contextualidade e a natureza localizada da ação, pois os cenários influenciam as ações e the atribuem significado, sendo relevantes na interpretação (GIDDENS, 1999). Por isso, reconhecemos que o contexto histórico em que a colaboradora deste estudo estava inserida contribuiu para que se adequasse ou resistisse às práticas normativas relacionadas à categoria de gênero, sobre os comportamentos que as mulheres poderiam assumir nas esferas pública e privada; assumindo práticas discursivas ou corporais, via esporte.

Heritage (1999, p. 358) consideraque "[...] a natureza do ajustamento entre as 'explicações' e suas circunstâncias é estabelecida por meio de um curso ativo de trabalho interpretativo". Qualquer uso da linguagem é motivado por vinculações contextuais, e faz com que "explicações ordinárias" dadas pelos atores sobre suas práticas sejam interpretadas contextualmente.

O processo de interpretação e significação também é influenciado pela distância entre 0 leitor e o autor do texto. Giddens (1999, p. 28) questiona a autonomia do texto enquanto objeto

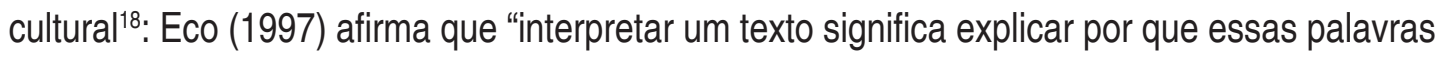
podem fazer várias coisas (e não outras) através do modo como são interpretadas". Com uma abordagem focalizada na interpretação do leitor, argumenta que quando um texto é produzido não será interpretado pelas intenções do autor, mas por uma rede complexa que envolve a história dos leitores-intérpretes. A intenção do leitor é ponto de partida para a interpretação $0^{19}$, devendo estar articulada com a obra/texto, o seu autor/produtor e o seu contexto de produção, o que é possível pela historicização do texto, enquanto "objeto cultural".

A atividade interpretativa trabalha com significados das diferentes linguagens: verbal, gestual e icônica, minimizando a indeterminação semântica ${ }^{20}$, pela constante negociação de

17 Em Análise do Discurso, o deslocamento de sentido, que contribui para que uma palavra ou texto assuma sentidos em função do contexto em que são ditas e do locus social de que as enuncia, é chamado de polissemia.

18 Para Giddens (1999), estes objetos culturais incorporam a polissemia como característica, tendo o texto como exemplo; pressupõem uma distância entre produtor e consumidor, envolvendo um processo de interpretação de seus significados; o consumidor (leitor) torna-se mais importante que o produtor (autor) do texto no processo interpretativo. 
sentidos. Pressupomos que a interpretação sobre as fontes orais e iconográficas (fotografias) que reunimos a respeito de nosso objeto resulta de nossa intertextualidade e memória discursiva ${ }^{21}$.

Considerando a possibilidade de uma interpretação plural, em virtude do leitorintérprete e dos objetos por ele interpretados, para análise e interpretação das fontes oral e icônica representadas pelo discurso da colaboradora, dos documentos e da imagem é que este estudo utiliza uma abordagem na interface da História Oral e da Semiótica com foco no leitor (ECO, 1997).

Enquanto texto, a imagem fotográfica ${ }^{22}$ compõe o conjunto de fontes iconográficas para a pesquisa histórica há décadas (MAUAD, 1996; SÔNEGO, 2010). Este avanço instaurou um novo desafio ao historiador: revelar o que não foi mostrado pelo olhar fotográfico, desvelando uma rede de significações cujos elementos interagem na composição de uma realidade contextual, ultrapassando a avaliação da fotografia como mera ilustração (CARDOSO, MAUAD, 1997).

O passado recente é cada vez mais conhecido através de imagens e a fotografia, entendida como "[...] a imagem, o registro visual fixo de um fragmento do mundo exterior, conjunto dos elementos icônicos que compõem o conteúdo e seu respectivo suporte" (KOSSOY, 2001, p. 39). A informação sobre os fatos comunicados pelo fotógrafo proporciona um conhecimento vital, mas o fotógrafo não tem um "olhar inocente", pois manipula as imagens, com o corte, a escolha do melhor ângulo, dirigindo a interpretação do observador (GASKELL, 1992). Logo, qualquer fotografia documenta, além de seu tema, a visão de mundo do seu autor (KOSSOY, 2001).

De modo geral, não devemos interpretar a fotografia como um espelho da realidade, mas uma pista, resíduo ou fragmento (SANTOS, FEIJÓ, 2000); um artefato que traz consigo elementos de uma história, de representações de uma época sobre noções de bem vestir, aspectos do desenvolvimento urbano e rural, flagrantes da vida real, memórias de guerra, normas de comportamento entre os sexos (CARDOSO, MAUAD, 1997).

O trabalho interpretativo da fotografia é viabilizado pela combinação com a consulta de outras fontes e com o contexto de sua produção, trazendo elementos para compreender-se a atitude dos personagens estáticos e mudos dos cenários parados no tempo ${ }^{23}$.

Conjugando essas informações ao conhecimento do contexto econômico, político e social, dos costumes, do ideário estético refletido nas manifestações artísticas, literárias e culturais da época retratada, haverá condições de recuperar microhistórias implícitas nos conteúdos das imagens. [...] 0 significado mais profundo da imagem não se encontra necessariamente explícito. [...] é imaterial; jamais foi ou virá a ser um assunto visível passível de ser retratado fotograficamente (KOSSOY, 2001, p. 117).

Assim, para análise e interpretação das fontes iconográficas do estudo, representadas pelas fotografias acerca da trajetória de Blanche Pironnet, optamos pela proposta de Kossoy (2001), que diferencia a análise iconográfica, cujo intuito é detalhar o conteúdo da imagem e

21 Intertextualidade é o conjunto de relações que um texto mantém com outros textos; enquanto a memória discursiva considera que uma interação verbal desenvolve-se no tempo, a partir da construção dialógica com outros discursos (MAINGUENEAU, 1998).

22 Melo (2010) afirma que um desafio na pesquisa em Histórica do Esporte é o uso de fontes de diferentes naturezas, buscando ampliar os olhares sobre o fenômeno esportivo, incluindo filmes, fotografias, pinturas, memórias, obras literárias, peças dramatúrgicas (teatro e dança), material publicitário, músicas, entre outros.

23 "É um engano pensar-se que o estudo da imagem enquanto processo de conhecimento poderá abdicar do signo escrito" (KOSSOY, 2001, p. 78). 
seus elementos icônicos formativos, situando-se ao nível da descrição, da análise iconológica relacionada ao ato interpretativo, do significado intrínseco (PANOFSKY, 2001) ${ }^{24}$, que incursiona, na cena representada, por conhecimentos sobre o momento histórico retratado. Para Barthes (1984, p. 148), é preciso "Ter acesso ao que há por trás: escrutar quer dizer virar a foto, entrar na profundidade do papel, atingir sua face inversa".

Kossoy (2001) propõe uma arqueologia do documento, pela reconstituição do processo que gerou o artefato e na análise dos elementos icônicos que compõem o registro visual. $O$ autor visa registrar e recuperar dados, reunindo tópicos relevantes na análise do exame iconográfico, a saber: a referência visual do documento, sua procedência, conservação, identificação, as informações sobre o tema retratado, o fotógrafo e a tecnologia utilizada na fotografia.

Cabe ao analista desvelar a "primeira realidade", que está por detrás da superfície fotográfica e seus elementos icônicos ("segunda realidade"), pois "a imagem não se esgota em si mesma. [...] há sempre muito mais a ser apreendido, além daquilo que é, nela, dado a ler ou ver" (PAIVA, 2002, p. 19). A imagem fotográfica deve ser utilizada como fonte histórica, ressaltando que o tema que ela aborda é um fragmento do real (PAIVA, 2002), determinado, recortado de um contínuo de vida, símbolos e representações, resultantes de possibilidades de ver, optar e fixar a realidade, de forma estética e ideologizada:

[...] fotografias apenas congelam, nos limites do plano da imagem, fragmentos desconectados de um instante de vida das pessoas, coisas, natureza [...]. Cabe ao intérprete compreender a imagem fotográfica enquanto informação descontínua da vida passada. [...] a leitura das mesmas se abre em um leque para diferentes interpretações a partir daquilo que o receptor projeta de si, em função de seu repertório cultural, [...] de seus preconceitos, de sua ideologia, razão porque as imagens sempre permitirão uma leitura plural (KOSSOY, 2001, p. 114-115).

Algumas fotografias do passado são imagens estáticas com assuntos estáticos, que podem ser representadas pelas duras e passivas expressões humanas dos álbuns de família, monumentos ou ruas quase sem vida. Ao se debruçar sobre a fotografia, as apropriações da imagem através do tempo e os silêncios que a compõem, é preciso fazer perguntas do tipo: Quando? Onde? Quem? Para quem? Para quê? Por quê? Como? Perguntas essas que buscamos responder em nossa análise.

\title{
4 PROPOSTA DE ANÁLISE
}

\begin{abstract}
$O$ ato de ver e de olhar não se limita a olhar para fora, [...] a olhar o visível, mas também, o invisível. [...] é o que chamamos de imaginação. [...] 0 que nós vemos é constantemente modificado por nosso conhecimento, nossos anseios, nossos desejos, nossas emoções, pela cultura, pelas teorias científicas [...] Oliver Sacks ${ }^{25}$
\end{abstract}

No intuito de efetuarmos uma análise iconográfica e interpretação iconológica, apresentamos uma fotografia de Blanche Pironnet (Ilustração 1) em companhia de um grupo de nadadores. 
Ilustração 1- de Blanche Pironnet em companhia de um grupo de nadadores.

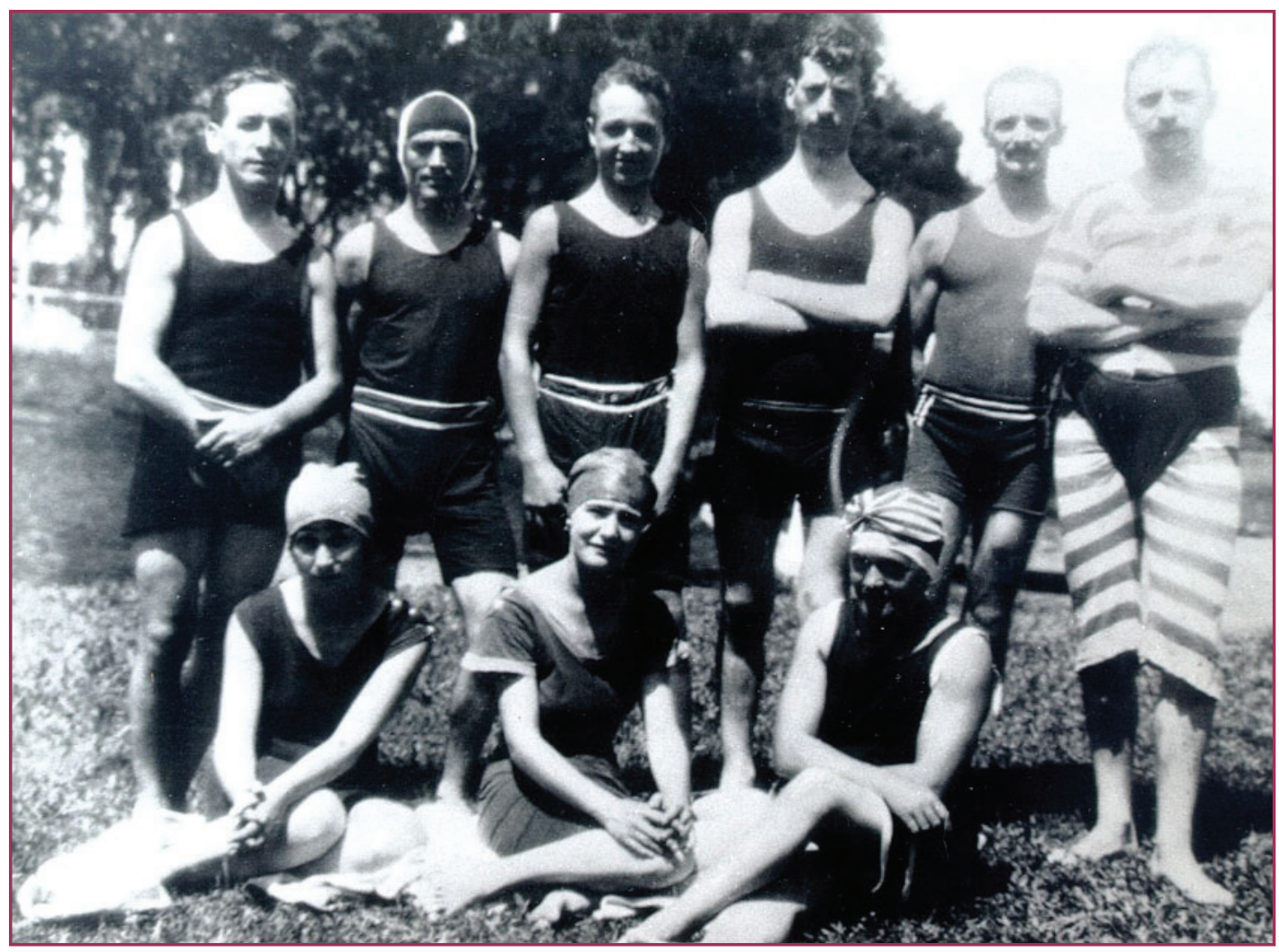

Fonte: Arquivo Histórico do Clube Esperia/SP

Análise iconográfica: iniciamos retificando a referência visual: esta é uma reprodução de uma fotografia produzida nos anos de 1920, por um fotógrafo desconhecido. Sua procedência advém de doação pela nadadora ao Arquivo Histórico do CE, localizado em São Paulo. Quanto à identificação e conservação, a imagem não possui título, encontrando-se em bom estado, arquivada em envelope, na Pasta "Blanche Pironnet", no $21-A$ (recortes doados pela nadadora).

Quanto às informações referentes ao tema, tudo indica que o registro visual foi feito à margem do rio Tietê, no $\mathrm{CE}$, onde, segundo Blanche, os rapazes e as moças costumavam se reunir para nadar no canal que o rio formava no terreno do clube. A presença de homens e mulheres devidamente uniformizados com toucas e maiôs constata que a foto pode ter sido tirada antes ou após uma sessão de treinamento. O homem de maiô listrado, à direita, destacase pela vestimenta diferente e pela aparência mais velha, podendo se especular ser o professor do grupo.

Não possuindo nenhum tipo de anotação, deduz-se que este é um grupo do CE que disputava competições. Como em 1919, somente Blanche participava das competições, a presença de outras duas mulheres não identificadas na foto contribui para se afirmar que foi produzida provavelmente após o ano de 1921, quando já havia outras paulistas nadando (DEVIDE, 2003, 2012).

Trata-se de uma fotografia que capta um fragmento da realidade, estático, resultado da pose do grupo devidamente construída e organizada hierarquicamente, que aguarda 0 clique do fotógrafo, eternizando a participação de homens e mulheres na natação paulista no início do século. 
Interpretação Iconológica: para fins de interpretação dos elementos constitutivos da fotografia, apontamos para aspectos da leitura de silêncios e valores sociais circulantes na sociedade da época, associados às questões de gênero ${ }^{26}$ na relação com o esporte.

Uma marca está relacionada à vestimenta, o típico maiô de lã descrito por Blanche, que tanto os homens como as mulheres deveriam usar nas aulas de natação. Ambos cobrindo parte das coxas e do tronco, inclusive no caso dos homens, pois era considerada uma falta de pudor expor o tronco masculino.

A organização do grupo, localizando os homens em um plano superior, de pé, e as mulheres em um plano inferior, sentadas em frente aos nadadores, configura uma hierarquia socioesportiva, delimitando o esporte como área de reserva masculina (HARGREAVES, 1993a; 1993b; MESSNER, 1994; DUNNING; MAGUIRE, 1997), ainda que ali, no chão, discretamente, repousasse aquela que vencia todos os homens: a pequena Blanche Pironnet.

De acordo com Théberge (1994), a reserva masculina no esporte se dá em três esferas: na organização, na administração e nas imagens veiculadas pela mídia, que tendem a sub-representar e subestimar as experiências esportivas das mulheres. Messner (1994) considera que as mulheres precisam romper resistências de gênero, que as interpretam como inferiores aos homens na prática atlética; transformam o corpo enquanto instrumento de ação, assumindo uma postura menos associada às mulheres, para incluírem-se na competição esportiva; ao contrário dos homens, para quem o esporte foi e tem sido um meio de construção da masculinidade (RUBIO, SIMÕES, 1999).

Barthes (1984) afirma que a pose é o que funda a fotografia; é quando uma coisa real se encontrou imóvel diante do olhar. Nesta fotografia, a pose viril e imponente de alguns nadadores, postos em primeiro plano versus a feminil, recatada e frágil das nadadoras, posicionadas no plano inferior, traz elementos importantes para a reconstrução do cenário esportivo da época. Isto pode ser interpretado pelo corpo ereto, os braços cruzados ou postos para trás, com os troncos projetados dos nadadores; em comparação ao corpo encolhido e curvado, às mãos cruzadas e pernas unidas, delicadamente posicionadas sobre a toalha branca que as protege do gramado onde repousam as três nadadoras.

Schpun (1999) analisou a cultura física na São Paulo da década de 1920, momento em que a urbanização exigia novas formas de apresentação corporal do homem e da mulher. As modalidades esportivas sofriam um processo de sexualização a partir da "naturalização" de atributos concebidos como femininos ou masculinos. 0 discurso normativo fazia do esporte veículo de fortalecimento da raça, manutenção da juventude e distinção social entre as elites e as classes populares. Enquanto para os homens o esporte se tornou um veículo de construção da virilidade, desenvolvimento muscular, coesão grupal e competitividade, para as mulheres ele visava à eugenia e à beleza, tornando-as fonte de prazer para os olhares masculinos.

Os corpos femininos são antes de mais nada preparados para serem vistos, para se exibirem. A beleza das formas, seja no que toca ao andar, à graça dos movimentos e dos gestos ou à expressão do rosto, permanece [...] o objetivo central de sua cultura corporal, a manifestação por excelência da "essência" feminina (SCHPUN, 1999, p. 74).

26 Interpretamos gênero como uma categoria relacional, referente às práticas sociais construídas historicamente no quotidiano, que tendem a sofrer transformações constantes; pode se relacionar aos comportamentos, atitudes e discursos esperados de ambos os sexos, nas diferentes esferas sociais, nas quais homens e mulheres interagem (SCOTT, 1992). 
As nadadoras brasileiras eram constantemente fotografadas com seus maiôs em poses sensuais, aproximando-as mais de modelos de feminilidade do que de atleticismo, configurando uma rede de estratégias para manter a graciosidade feminina, ao lado da prática esportiva não competitiva (DEVIDE, 2012).

Outro aspecto importante, dada a semelhança e o depoimento de Blanche Pironnet, é a suposta presença masculina de José Pironnet, posicionado atrás desta colaboradora, como um companheiro e guardião da irmã, simbolizando a segurança que a acompanhava nas sessões de ginástica ministradas pelo pai, pelas manhãs, e nos treinos de natação no CE, nas tardes paulistas.

A presença de outras nadadoras atesta o aumento da participação feminina na natação em São Paulo. Segundo Nicolini (2001), até o final da década de 1920 causava estranheza à sociedade assistir a mulheres remando em regatas ou em treinamento. Na época acreditava-se que a natação era um esporte que dispensava a força, sendo menos atlético; e também, por ser realizada ao ar livre e na água, tornava-se a atividade por excelência, higiênica e capaz de trazer benefícios estéticos e fisiológicos ao corpo feminino. Como comenta Maria Lenk (1986, p. 17), "[...] a natação gozava de fama de dispensar a força física muscular, portanto, não prejudicando as virtudes femininas de graciosa fragilidade impostas pelo machismo dominador".

$O$ retrato destas mulheres junto aos homens oferece outra leitura: 0 uso do capital simbólico - no caso, um corpo de classe (PRIORE, 2000), belo, esculpido pela prática do esporte, que fotografado, exposto publicamente e cortejado, conferiu, ao lado do discurso eugênico do Estado e dos intelectuais ${ }^{27}$, que preconizavam a prática da natação como a atividade esportiva ideal para as mulheres, uma forma de poder simbólico, que permitiu que essas mulheres da elite ingressassem na esfera da competição esportiva sem maiores resistências sociais.

\section{CONSIDERAÇÕES FINAIS}

O presente estudo teve como objetivo refletir sobre o uso da linguagem e da imagem, como fontes para a investigação histórica do esporte, a partir da História Oral da nadadora Blanche Pironnet, uma referência no estudo da História das Mulheres no esporte, no início do século XX. A partir de uma reflexão sobre a interpretação da linguagem e da imagem, como fontes relevantes da pesquisa histórica do esporte, apresentamos a trajetória desta mulher no esporte na cidade de São Paulo e Rio de Janeiro, entre as décadas de 1910-1920.

$\mathrm{Na}$ sua complexidade, os dados reunidos nesta pesquisa trazem à tona questões que podem ser problematizadas com novos olhares, contribuindo para uma reflexão sobre as possibilidades de uso da metodologia pautada na análise do discurso e na análise iconográfica e iconológica da imagem no âmbito da pesquisa sobre História do Esporte; neste caso, na História das Mulheres no Esporte, fomentando uma interpretação crítica sobre o processo de inserção e manutenção das mulheres brasileiras no esporte no Brasil, no qual a natação feminina constituiu uma das portas de entrada principais.

27 "A educação physica da mulher deve constar de: a) jogos infantis [...]; b) gymnastica sueca, principalmente appropriada á funcção respiratoria e á bacia e aos membros inferiores; c) esportes, taes como dança clássica, ao ar livre, pedestrianismo [...]; e, finalmente, a natação que é o esporte utilitário de maior capacidade hygienica e morphogenica [...]" (AZEVEDO, 1920, p. 46). 


\section{REFERÊNCIAS}

ALEXANDER, Jeffrey C. A importância dos clássicos. In: GIDDENS, Anthony; TURNER, Jonathan (Orgs.). Teoria social hoje. São Paulo: Unesp, 1999. p. 23-89.

AZEVEDO, Fernando. Educação physica feminina. Sports, São Paulo, anno I, v. 2, p. 46, 1920.

BARTHES, Roland. A Câmara Clara. Rio de Janeiro: Nova Fronteira, 1984.

BOURDIEU, Pierre. 0 poder simbólico. São Paulo: Bertrand Brasil, 2001.

BURKE, Peter. Abertura: a nova história, seu passado e seu futuro. In: BURKE, Peter. (Org.). A escrita da história: novas perspectivas. São Paulo: Unesp, 1992. p. 9-37.

CARDOSO, Ciro F.; MAUAD, Ana. M. História e Imagem: os exemplos da fotografia e do cinema. In: CARDOSO, Ciro F.; VAINFAS, Ronaldo. (Orgs.). Domínios da História: ensaios sobre teoria e metodologia, 1997. p. 401-417.

COSTA, Jurandir F. Pragmática e processo analítico: Freud, Wittgenstein, Davidson, Rorty. In: COSTA, Jurandir F. (Org.). Redescrições da psicanálise. Rio de Janeiro: Relume Dumará, 1994. p. 9-59.

COULON, Alain. Etnometodologia. Petrópolis,RJ: Vozes, 1995.

DEVIDE, Fabiano P. História das Mulheres na Natação Feminina no Brasil no século XX: das adequações às resistências sociais. 347p. 2003. Tese (Doutorado) - Universidade Gama Filho, Rio de Janeiro, 2003.

DEVIDE, Fabiano P. História das Mulheres na Natação Feminina no Brasil no século XX: das adequações às resistências sociais. São Paulo: Hucitec, 2012.

DUNNING, Eric; MAGUIRE, Joseph. As relações entre os sexos no esporte. Estudos Feministas, v. 5, n. 2, p. 312-348, 1997.

ECO, Umberto. Interpretação e superinterpretação. Rio de Janeiro: Martins Fontes, 1997.

ETIÉNNE, François. A fecundidade da história oral. In: FERREIRA, Marieta de M.; AMADO, Janaína (Orgs.). Usos \& abusos da história oral. Rio de Janeiro: FGV, 1996. p. 4-13.

FEDERAÇÃO BRASILEIRA DAS SOCIEDADES DE REMO (FBSR). Programma Official dos Concursos Aquaticos promovidos pelo Club de Natação e Regatas a realizarem-se em 3 de abril de 1921 na enseada de Botafogo. Rio de Janeiro, 1921.

FERREIRA, Marieta de M.; AMADO, Janaína (Orgs.). Usos \& abusos da história oral. Rio de Janeiro: FGV. 1996. p. vii-Xxv.

GASKELL, Ivan. História das imagens. In: BURKE, Peter (Org.). A escrita da história: novas perspectivas. São Paulo: Unesp, 1992. p. 237-272.

GIDDENS, Anthony. Estruturalismo, pós-estruturalismo e produção da cultura. In: GIDDENS, Anthony; TURNER, Jonathan (Orgs.). Teoria social hoje. São Paulo: Unesp, 1999. p. 281-318.

HARGREAVES, Jennifer A. Gender on sports agenda. In: INGHAM, Alan G.; LOY, John W. (Eds.). Sport in social development: traditions, transitions, and transformations. Champaign: Human Kinetics. 1993a. p. 167-185. 
HARGREAVES, Jennifer A. The Victorian cult of the family and the early years of female sport. In: DUNNING, Eric G.; MAGUIRE, Joseph A. (Eds.). The sport process: a comparative and developmental approach. Champaign: Human Kinetics, 1993b. p. 71-83.

HERITAGE, John. Etnometodologia. In: GIDDENS, Anthony; TURNER, Jonathan H. (Orgs.). Teoria social hoje. São Paulo: UNESP, 1999. p. 321-384.

JOUTARD, Philippe. História oral: balanço da metodologia e da produção nos últimos 25 anos. In: FERREIRA, Marieta de M.; AMADO, Janaína (Orgs.). Usos \& abusos da história oral. Rio de Janeiro: FGV. p. 43-62.

KOSSOY, Boris. Fotografia \& História. São Paulo: Ateliê Editorial, 2001.

LENK, Maria. Braçadas \& abraços. Rio de Janeiro: Bradesco, 1986.

LOZANO, Jorge E. A. Prática e estilos de pesquisa na história oral contemporânea. In: FERREIRA, Marieta de M.; AMADO, Janaína (Orgs.). Usos \& abusos da história oral. Rio de Janeiro: FGV, 1996. p. 15-31.

MAINGUENEAU, Dominique. Termos-chave em análise do discurso. Belo Horizonte: UFMG, 1998.

MALUF, Marina; MOTT, Maria L. Recônditos do feminino. In: SEVCENKO, Nicolau (Org.). História da vida privada no Brasil: República: da belle époque à era do rádio. São Paulo: Cia das Letras, 1998. v. 3, p. 367-421.

MAUAD, Ana M. Através da imagem: fotografia e história - interfaces. Tempo, v. 1, n. 2, p. 73, 98, 1996.

MEIHY, José C. S. B. Manual de história oral. São Paulo: Loyola, 1996.

MELO, Victor. A. História do Esporte: panorama e perspectivas. Fronteiras, v. 12, n. 22, p. 11-35, 2010.

MESSNER, Michael. Sports and male domination: the female athlete as a contested ideological terrain. In: BIRREL, Susan; COLE, Cheryl L. (Eds.). Women, sport, and culture. Champaign: Human Kinetics, 1994. p. 65-80.

NICOLINI, Henrique. Tietê: o rio do esporte. São Paulo: Phorte, 2001.

PAIVA, Eduardo F. História e Imagens. Belo Horizonte: Autêntica, 2002.

PANOFSKY, Erwin. Significado nas artes visuais. São Paulo: Perspectiva, 2001.

PÊCHEUX, Michel. Semântica e discurso: uma crítica à afirmação do óbvio. Campinas: Unicamp, 1995.

PRIORE, Mary Del. Corpo a corpo com a mulher: pequena história das transformações do corpo feminino no Brasil. São Paulo: SENAC, 2000.

RORTY, Richard. Contingência, ironia e solidariedade. Lisboa: Presença, 1994.

RUBIO, Kátia; SIMÕES, Antônio C. De protagonistas a espectadoras: a conquista do espaço esportivo pelas mulheres. Movimento, v. 11, p. 50-56, 1999.

SANTOS, Edmilson S. dos; FEIJÓ, Rita de C. Construindo História com Fotografias Desportivas. In: CONGRESSO BRASILEIRO DE HISTÓRIA DA EDUCAÇÃO FÍSICA, ESPORTE, LAZER E DANÇA.7., 2000. Anais... Gramado:UFRGS, 2000. p. 161-165. 
SCHPUN, Mônica R. Beleza em jogo: cultura física e comportamento em São Paulo nos anos 20. São Paulo: Boitempo, 1999.

SCOTT, Joan. História das mulheres. In: BURKE, Peter. (Org.). A escrita da história: novas perspectivas. São Paulo: Unesp, 1992. p. 62-95.

SHARPE, Jim. A história vista de baixo. In: BURKE, Peter. (Org.). A escrita da história: novas perspectivas. São Paulo: Unesp, 1992. p. 39-62.

SOIHET, Rachel. História das mulheres. In: CARDOSO, Ciro F.; VAINFAS, Ronaldo (Orgs.).

Domínios da história. Rio de Janeiro: Campus, 1997. p. 275-296.

SÔNEGO, Márcio de J. F. A fotografia como fonte histórica. Historiæ, v. 1, n. 2, p. 113-120, 2010.

THÉBERGE, Nancy; BIRRELL, Susan. The sociological study of women and sport. In: COSTA, Margaret; GUTHRIE, Sharon R. (Eds.). Women and sport. Champaign: Human Kinetics, 1994. p. 323-328.

THOMPSON, Paul. A voz do passado: história oral. São Paulo: Paz e Terra, 1992. 